\title{
Analysis of the role of symbolic language in oil painting creation
}

\author{
Cui Xu ${ }^{1, a}$ Qiulin $Q u^{2, b}$ \\ ${ }^{1}$ Changchun institute of technology, visual arts, Jilin 130000, China \\ ${ }^{2}$ Changchun normal university academy of fine arts, Jilin 130000, China \\ axucuixucui@126.com, ${ }^{b} 757468808 @ q q . c o m$
}

\section{Keywords: Symbolic language, Oil painting, Artistic conception, Age characteristics}

\begin{abstract}
Oil painting is a western painting type, since it was introduced into China, because China's specific "shape write god", "me like and don't like" the influence of aesthetic thought, to make it more and more Chinese, localization, in the development process, appeared a batch of the pursuit of image and painting blend of artists, these artists have skilful use of some different symbolic language to express the emotion, the pursuit of "body and pick up and condition, and body and gratitude" aesthetic character, showed a strong national aesthetic consciousness. Based on this, the author tries to explore the symbolic language in the use of the role of in painting creation, to inspire the practice of the oil painting creation.
\end{abstract}

\section{Introduction}

In the modern oil painting creation, symbolic language artist to be more and more attention, many artists have symbolic language to research and apply, thus has obtained the good artistic effect. Symbolic language in painting creation in which it can be to be a focus in the study of this article.

\section{The role of symbolic language in oil painting creation}

Build the culture of poetic artistic conception .Imagery oil painting is a special product in China after the introduction of Western oil painting into China, and it Is a typical oil painting in China Like, reflecting a kind of "heart outside things", "things I for a" of China's Oriental cultural realm. In this type of painting, artists are clever use of the symbolic language of different types to achieve this realm, symbolic language here can be shaped, can also be a color screen, because the use of these symbolic language has its unique cultural conception. We take Guanzhong Wu works as an example, As shown in figure1, the landscape paintings can be said to be the vivid, the color of European painting and traditional Chinese rich and delicate artistic spirit and aesthetic ideal together a masterpiece. This is his oil painting "coastal fish village", is a kind of exploration of oil painting in china, Point, line, face of the screen to achieve the ultimate, symbolic language where the point line surface is the master's works, the symbolic language and picture color skillfully combined very well reflected in the mist of the white walls and black tiles waterside cottage, the color of the picture is fresh, create a an elegant, quiet spiritual realm, the picture had a lyrical artistic culture, reflects the artist to Chinese peculiar to the natural heart experience, expression and understanding of the nature in the art of painting, the picture of the strong oriental form of means is a strong sense of Chinese culture. Reflect the cultural characteristics of Chinese poetic, his exploration is a milepost significance. Jinyan Zheng is also a representative image of painting, As shown in figure2,his works are also integrated into the various image symbols China connotations of traditional culture, the picture conveys relaxed and thoughtful artistic culture. As shown in figure2,Below is his "Lotus" scene, but also clever use of color and point, line and surface combined with the expression of Misty and ethereal lotus, Like works in written form, the clear bosom, conveys the painter poetic experience of life, "with the four to sigh and think things have passed away, looking. Sad falling leaves in autumn, The tender branches in the spring . " Painter with freehand brushwork in traditional Chinese painting technique for image on the like and unlike, highlights the Chinese unique cultural ethos. 


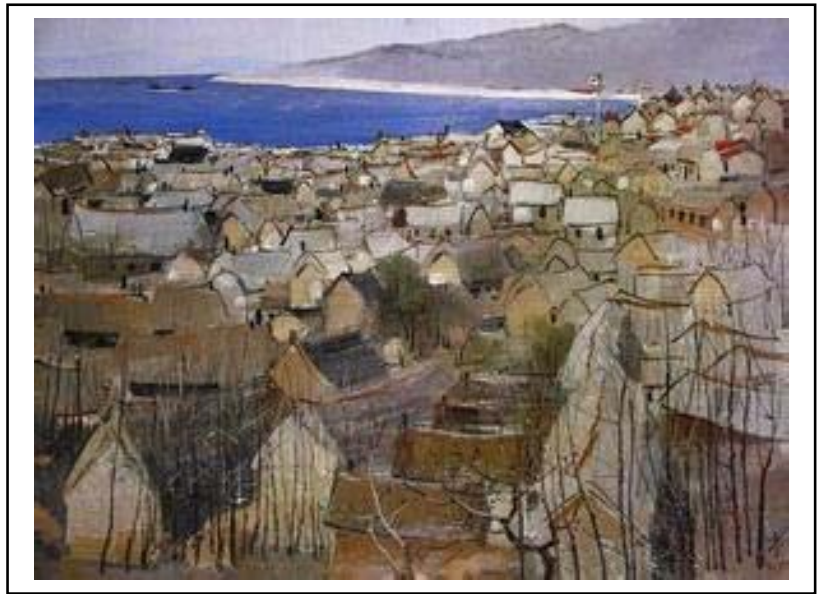

FIG. 1 , oil painting , "coastal fish village"

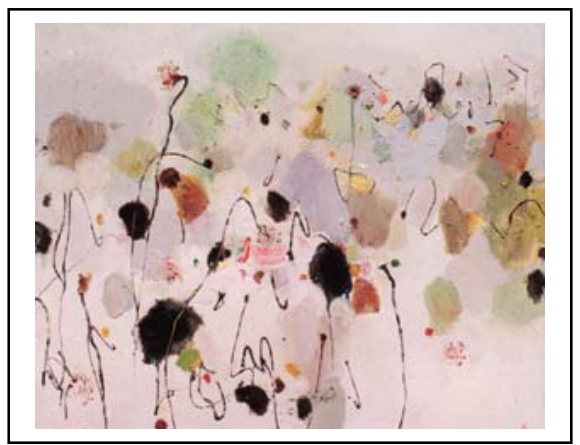

FIG. 2, oil painting , " the scenery of Lotus pond "

Express the artist's aesthetic emotion. At present, a lot of oil painting artist's work is to explore Chinese painting style, pay attention to the painter subjective model of emotional expression. Their work did not have the emotional factors, pay more attention to spiritual expression. In this kind of work the symbols in a certain sense, so in their work, is particularly important to the selected symbol. Xiao dong Liu is a well-known domestic new generation artists, his works always got to respect for reality. As shown in figure3, Mr. Liu's paintings, depicts ordinary people in real life a moment scene, warmth, tonal and pure and fresh quietly elegant, full of thick life breath. Series of his works are "close", by depicting real life will not be attention to detail, performance object the reality of the situation and mental outlook, the closer the images of screen image is the painter of symbolic language, the language of the refining and reflect the painter focus on reality is applied in the real aesthetic emotion, every ordinary characters in his works are different degree of terrain in pairs stared at the meaning of life.

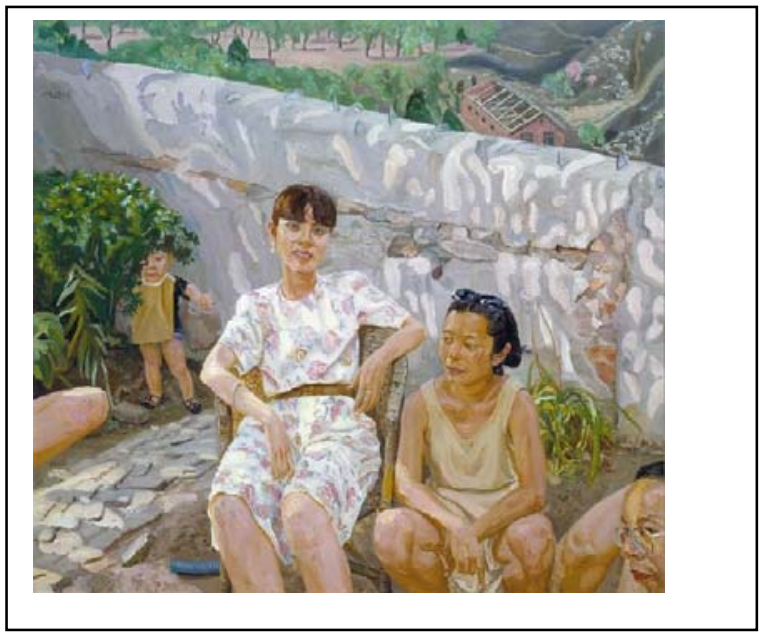

FIG.3, oil painting , " Life in an instant " 
Arouse the aesthetic feeling of appreciation. Artists make art, an unavoidable realistic problem is How to stimulate the appreciation imagination and sensory experience, Oil painting by mutual hinted that the symbol of rich visual experience and psychological association. Balzac once said: "really understand poetry will only in the author verses revealed nothing thing to his heart." This sentence can use oil painting Through the form of oil painting color symbol language, reveals the painter's thought of emotions and ideas at the same time, also can make people produce a kind of hazy feeling view picture, the viewer through its own cultural accumulation and experience, and constantly, and a little bit of understanding the deep connotation, the aesthetic feelings from work, higher than work. Why not Xiao gang Zhang just is the representative artists, his painting is also "extended family" to old photos with time characteristics and the family as a creative element. As shown in figure4, this is Mr. Zhang's blood series - big family "oil painting, picture used a hazy, insipid painting language shows the spirit of his idea of the blood and the history of the family, the author through to the oil painting language, reflected his nostalgia for growth history, express the artist's aesthetic emotion, the frame and tidy and standard posture, dull, apathy, modeling of expression characters are artists selected symbol, This iconic symbol not only renders a nostalgic aura, but also reflects China's ordinary fuzzy character, emphasizes the commonality, implicative, neutral and poetic aesthetic pursuit, he can easily mark of the personal life and time will be together, let the viewer is easy to produce the strong emotional resonance.

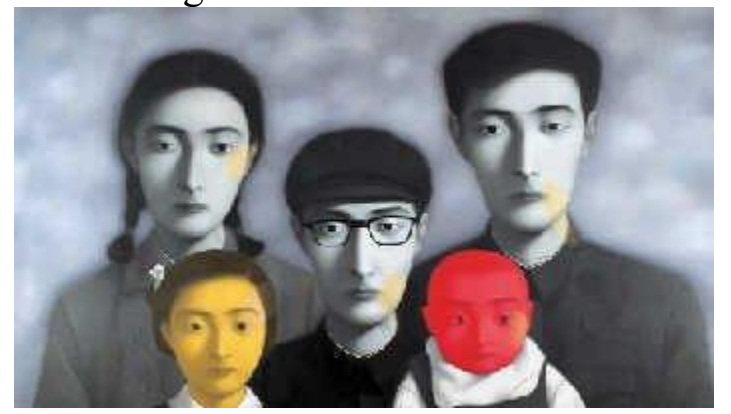

FIG.4, oil painting, "blood series - big family "

Works reflect era characteristics. Jun Leng is the leading Chinese contemporary realism oil painting. As shown in figure $5 \backslash 6$,His works "infancy" in shaping the image of squeezed, there is a profound social point, these will be squeezed, deformation, damage is the image of the what we call sign, can cause our experience for the suffering of life and the social reality of critical care. By means of this, the painter symbols express the reality pressure by environment, his pictures hung over a mind cannot release repressed. Painter said, " freedom is humanity's side, but freedom of soul is more vulnerable to oppression, I sometimes is more like a critical realism writer". Painter through his capture symbols to reflect the contemporary society of the rapid economic growth to bring the huge pressure of people's hearts, good reflected The Times characteristics.
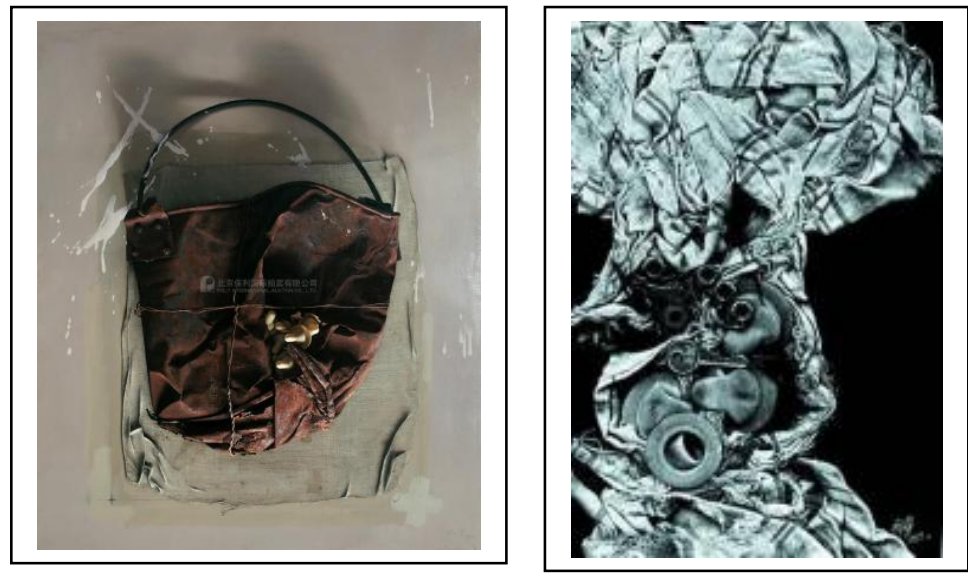

FIG.5\6, oil painting, "infancy" 


\section{Summary}

Chinese and western art ideas, more and more of the writing form of fusion, symbolization in the oil painting language into is the needs of the development of times, it into for the oil painting creation opens up a new field of vision, widen the train of thought for the development of Chinese modern oil painting.

\section{References}

[1] Feng Wu, the artistic symbolic aesthetics: Susan Lundgren symbol aesthetics research, Beijing broadcasting institute press, 2008 (9).

[2] Jian-zhang Yu, Shuxian Ye, symbols, language and art, Shanghai people's publishing house, 1988.

[3] Susan lundgren, the emotion and form, China social sciences press, 1986.

[4] PengLv, "Chinese contemporary art history", Hunan fine arts publishing house, 2000.

[5] Qinguo Zhao, Art language, jinan, the Yellow River publishing house, 2003

[6] Jia Chen, Analysis "symbolic" phenomenon in Chinese contemporary art, nanjing art institute, 2010 